\section{SOTAQUE PREMIADO: A INCIDÊNCIA DE MEDALHAS NATURALIZADAS NOS JOGOS OLÍMPICOS RIO 2016}

\author{
AWARDED ACCENT: OCCURRENCE OF "NATURALIZED MEDALS" IN \\ THE RIO 2016 OLYMPICS CP
}

ACENTO PREMIADO: LA INCIDENCIA DE MEDALLAS NATURALIZADAS

EN LOS JUEGOS OLÍMPICOS DE RÍO 2016 C P

doi) https://doi.org/810.22456/1982-8918.109549

(iD) Diogo Bonin Maoski* <bonin.maoski@gmail.com>

(iD) Ana Paula Cabral Bonin Maoski*<bonin@utfpr.edu.br>

(i) Thiago de Oliveira Santos ${ }^{* *}<$ thiago_os@hotmail.com>

(iD) Fernando Marinho Mezzadri*** <fmezzadri@uol.com.br>

(iD Thiago Cavalcante Nascimento****

<prof.thiagocnascimento@gmail.com.br>

\footnotetext{
*Universidade Tecnológica Federal do Paraná. Curitiba, PR, Brasil.

**Universidade Europeia. Lisboa, Portugal.

***Universidade Federal do Paraná. Curitiba, PR, Brasil.

****Escola de Gestão e Economia (DAGEE). Curitiba, PR, Brasil.
}

Resumo: O objetivo do estudo foi descrever a incidência de medalhistas olímpicos naturalizados nos Jogos Olímpicos do Rio de Janeiro em 2016. Trata-se de uma pesquisa quantitativa de natureza descritiva. Os resultados demonstram que 6,7\% das medalhas foram distribuídas para atletas naturalizados, o que corresponde a $6,9 \%$ do total de atletas vencedores de medalhas. Os resultados apontam ainda que a maior parte do fluxo migratório de atletas medalhistas ocorreu de países de menor desempenho econômico para os de maior desempenho econômico e de países de menor desempenho olímpico para países de maior desempenho olímpico. As conclusões indicam que o atual contexto de naturalização de atletas tende a ser mais benéfico aos países de grande desempenho econômico e olímpico, bem como aos países de grande desempenho econômico, mas sem tradição no esporte, sendo desvantajoso aos países de baixo desempenho econômico.

Palavras chave: Esportes. Migração humana. Atletas. Medalhas.
Recebido em: 01 dez. 2020 Aprovado em: 16 out. 2021 Publicado em: 13 nov. 2021

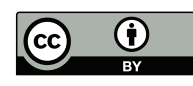

Este é um artigo publicado sob a licença Creative Commons Atribuição 4.0 Internacional (CC BY 4.0).

eISSN: $1982-8918$ 


\section{INTRODUÇÃO}

Rio de Janeiro, trigésima primeira edição dos Jogos Olímpicos modernos, uma partida de vôlei se inicia nas areias da Arena de Copacabana; de um lado uma equipe do Catar e do outro lado uma equipe espanhola. A equipe espanhola é formada por dois espanhóis, enquanto a equipe catari é formada por um brasileiro e um senegalês. Alguns quilômetros de distância da praia carioca, Slobodan Soro, medalhista olímpico em Londres-2012 pela Sérvia prepara-se para participar de uma partida de polo aquático, porém desta vez a sua touca terá uma cor diferente e pertencerá ao Brasil. Em outro local da sede olímpica, mais precisamente no estádio Nilton Santos, longe da areia e da água, Ruth Jebet, queniana de nascimento, conquista o primeiro ouro da história do... Bahrein.

Os Jogos Olímpicos e Paralímpicos Rio-2016 encerraram uma década de grandes eventos esportivos ocorridos no Brasil. A realização dos Jogos Pan e Parapan-Americanos (2007), Jogos Mundiais Militares (2011) e da Copa do Mundo FIFA (2014) não foi suficiente para suprir as expectativas positivas de grande sucesso na organização e realização de eventos de tamanha magnitude no cenário esportivo mundial, sendo que muito se discutiu e se discutirá acerca da viabilidade dos eventos e dos seus legados (BETTINE; GUTIERREZ; GRAEFF, 2018; CHEQUER; MARTINS; SILVA, 2019; PAES; AMARAL, 2017; SANTOS, 2017; SILVA et al., 2015). Todavia, entre os diversos temas envolvidos durante a preparação e realização dos Jogos Olímpicos no Brasil, destaca-se aquele que compôs o parágrafo inicial do presente estudo: a migração de atletas.

Apesar da existência de algumas vozes dissonantes (JANSEN; ENGBERSEN, 2017; JANSEN; OONK; ENGBERSEN, 2018), grande parte da literatura especializada aponta que a migração laboral é uma característica consolidada e crescente no esporte globalizado (ANDREFF, 2010; FAGGIANI et al., 2016; HOROWITZ; MCDANIEL, 2015), envolvendo o deslocamento de técnicos, auxiliares, agentes administrativos, cientistas do esporte e, sobretudo, atletas (ALMEIDA; RUBIO, 2018; PONTES et al., 2018)

Simiyu Njororai (2010) aponta que na vanguarda dos estudos sobre os fluxos migratórios de atletas estavam os geógrafos do esporte, seguidos dos sociólogos e historiadores sociais. Com o tempo, estudos sobre a migração de atletas estrangeiros passaram a contemplar diferentes esportes, como atletismo, beisebol, críquete, hóquei no gelo, rúgbi, futebol americano e futebol. Conforme aponta Maguire (2007), as migrações são eventos complexos que sofrem diferentes tipos de pressões, sendo um processo modelado pela interação de fatores econômicos, políticos, históricos, geográficos, sociais e culturais.

Nesse sentido, diversos estudos relacionados ao processo migratório de atletas foram realizados em diferentes países e levando em consideração distintos contextos sociais, econômicos e esportivos (AGERGAARD, 2017; BESNIER, 2015; CHIBA; EBIHARA; MORINO, 2001; DIMEO; RIEIRO, 2009; MAGUIRE, 1996; MELO; ROCHA JUNIOR, 2012; REICHE; TINAZ, 2019; RIBEIRO et al., 2013; RUBIO, 2017; SHOR; YONAY, 2010; SOCA, 2012; TIESLER, 2016). Porém, como analisado por Faggiani et al. (2016), ainda não há na literatura um termo único para definir este 
processo de transição de cultura por partes dos atletas, sendo as expressões mais comuns: transição migratória, migração e aculturação.

As principais razões que levam um atleta a migrar para outros países estão relacionadas às questões financeiras, ao desenvolvimento e reconhecimento no esporte e às oportunidades de expandir as experiências em outras culturas (PONTES et al. 2018; RICHARDSON et al. 2012; SIMIYU NIJORORAI, 2010). Já no que diz respeito à perspectiva dos países que recebem os atletas, o processo de naturalização propicia vantagens, como o aumento das receitas com publicidade e patrocínio, atração da mídia para as respectivas nações vencedoras, prestígio internacional, conscientização do esporte e melhora no desempenho esportivo (HOROWITZ; MCDANIEL, 2015).

Desse modo, a despeito da migração no esporte ser um fenômeno existente em diferentes esportes e ligas esportivas (basquete, hóquei, beisebol, handebol e com mais ênfase no futebol), diversos autores passaram a problematizar a crescente "fuga de músculos" no ambiente do Jogos Olímpicos (ANDREFF, 2010; SIMIYU NIJORORAI, 2010). Conforme apontam Horowitz e McDaniel (2015), são inúmeros os relatos de países que facilitam os processos de naturalização e que "recrutam" abertamente atletas para aumentar a sua contagem de medalhas e, por conseguinte, melhorar a sua classificação no quadro geral dos Jogos Olímpicos.

De acordo com Spiro (2012), não há dúvidas de que no contexto dos Jogos Olímpicos houve um aumento nos casos de cidadanias adquiridas com base em uma perspectiva instrumental, ou seja, para fins exclusivos de competição, em que a ligação entre o atleta e o país pelo qual está competindo é tênue ou inexistente. Conforme aponta o autor, são três os componentes principais que interferem no regime da nacionalidade no ambiente olímpico: a Carta Olímpica, as regras das federações esportivas internacionais e as leis relacionadas à naturalização.

Em consonância com a Regra $n^{\circ} 41$ da Carta Olímpica, um competidor deve ter a nacionalidade do país que representa, sendo permitido que tenha mais de uma nacionalidade. Entretanto, se um atleta disputar alguma competição por um determinado país, terá que aguardar pelos menos três anos para poder transferir a sua filiação e assim competir por outra nação. Esse prazo pode ser reduzido ou ainda cancelado caso o Comitê Olímpico Internacional (COI), os comitês olímpicos dos países envolvidos e a federação que representa o esporte do atleta cheguem a um acordo (IOC, 2020).

Entretanto, apesar de muitos esportes incorporarem as regras da Carta Olímpica, alguns adotam requisitos adicionais, como, por exemplo, o futebol e o basquete. Nesses esportes, um atleta que representar um país em alguma competição internacional depois de completados 18 anos de idade é, na grande maioria dos casos, impedido de competir por outra nacionalidade. No hóquei no gelo, por exemplo, é permitida apenas uma transferência irrevogável de nacionalidade. Em outros esportes, como o tiro com arco, hóquei no campo, triatlo e pentatlo, além de cumprir os períodos de transição impostos pela Carta Olímpica, são necessários outros requisitos, dentre eles, o estabelecimento de residência no país em que se pretende filiar (SPIRO, 2012). 
Ainda de acordo com Spiro (2012), a chave do aumento das naturalizações instrumentais é um relaxamento dos países em relação ao tema. Se anteriormente, sobretudo em um contexto de Guerra Fria, a mudança de nacionalidade poderia ser vista como uma traição, as modificações nas normas de cidadania contribuíram para um contexto em que um atleta pode defender uma bandeira diferente da sua pátria original sem o receio das retaliações anteriormente vivenciadas. De forma semelhante, Maguire (2007) ressalta que, após as revoluções iniciadas no final da década de 1980, houve uma abertura da Europa Oriental e, dessa forma, húngaros, tchecos, eslovenos, romenos - e, mais posteriormente, bósnios e croatas - também começaram a fazer parte desse processo de migração e naturalização.

Cabe ressaltar que, atualmente, são diversos os processos de naturalização no ambiente esportivo. Alguns países a determinam com base no local de nascimento (jus soli), enquanto outros pela ancestralidade (jus sanguinis). Todavia, ela também pode ser adquirida por meio do estabelecimento de residência (jus domicilli) ou do casamento com um cidadão nativo (jus matrimonii), dentre outros (JANSEN; OONK; ENGBERSEN, 2018).

Além dos fatores já evidenciados, outra característica que influenciou no aumento dos processos de naturalização no contexto do esporte olímpico foi a gradativa substituição dos atletas amadores pelos atletas profissionais. De acordo com Rubio (2017), a partir dos Jogos Olímpicos da década de 1980, especialmente a edição realizada em 1992 na cidade de Barcelona, surgiu maior necessidade de equipamentos e regimes de treinamentos mais especializados, inflacionando o custo do esporte olímpico a um ponto em que algumas federações e países ainda não são capazes de suportar. Em contrapartida, nos países em que a gestão do esporte se tornou profissionalizada, a atividade dos atletas criou diversos postos de trabalho, atraindo estrangeiros de diferentes continentes.

Desse modo, o relaxamento nas normas de naturalização e o processo de profissionalização do esporte olímpico são fatores que culminaram no aumento do interesse dos países em melhorar seu desempenho olímpico por meio de atletas naturalizados. Assim, verifica-se que incentivos às transferências de nacionalidade parecem ter aumentado à medida que as barreiras foram reduzidas, sendo que, atualmente, diversos países oferecem grandes incentivos financeiros aos seus futuros atletas (SPIRO, 2012; RUBIO, 2016).

Especificamente quanto ao contexto migratório de atletas olímpicos no Brasil, Almeida e Rubio (2018) apontam que até a edição olímpica Rio-2016 o país havia sido representado por 1.796 atletas, sendo que, destes, 32 nasceram em outros países. Todavia, na edição carioca dos Jogos, a equipe brasileira contou com um total de 23 atletas de outras origens. Esse aumento expressivo não é exclusividade do Brasil, sendo uma tendência observada nas demais nações, conforme foi possível observar em Londres-2012 (ALMEIDA; RUBIO 2018) e, ao que tudo indica, será possível observar também na edição dos Jogos a ser realizada no Catar (ANDREFF, 2010; REICHE; TINAZ, 2019).

Dessa forma, considerando a carência de pesquisas que explorem o impacto das naturalizações no desempenho esportivo dos países nos Jogos Olímpicos 
(HOROWITZ; McDANIEL, 2015) e que analisem a performance dos atletas naturalizados (NASCIMENTO et al., 2020), o presente estudo tem como objetivo central descrever a incidência de medalhas conquistadas por atletas naturalizados nos Jogos Olímpicos Rio-2016.

Além do objetivo central, foram traçados os seguintes objetivos específicos: apontar quais países mais "exportaram"1 medalhas e quais países mais "importaram" medalhas; analisar o fluxo migratório de medalhistas naturalizados em relação ao desempenho econômico dos países; analisar o fluxo migratório de medalhistas naturalizados em relação ao desempenho olímpico dos países.

Por fim, destaca-se o importante papel interdisciplinar desta pesquisa, haja vista que compreender a migração de atletas olímpicos pode contribuir não apenas ao conhecimento do campo esportivo, mas também no que diz respeito ao debate que envolve aspectos econômicos, antropológicos e sociais acerca do fluxo migratório de mão de obra altamente qualificada.

\section{PROCEDIMENTOS METODOLÓGICOS}

A perspectiva metodológica adotada no presente estudo consiste em uma abordagem quantitativa de natureza descritiva (RICHARDSON, 2012; SAMPIERI; COLLADO; LUCIO, 2013). Cabe salientar que, dada a sua natureza multifacetada, avaliar a troca de nacionalidade está longe de ser um exercício simples. Para ser capaz de mapear os padrões de migração olímpica, o ideal é analisar dados biográficos detalhados de cada atleta de todos os países participantes (JANSEN; OONK; ENGBERSEN, 2018). Todavia, conforme apontam Asis e Piper (2008), as limitações na disponibilidade de dados confrontam frequentemente os pesquisadores da migração laboral, não sendo diferente no ambiente esportivo.

Conforme apontado por Horowitz e McDaniel (2015) e Jansen e Engbersen (2017), em virtude do Comitê Olímpico Internacional não contar com uma base de dados oficial que contemple os locais de nascimento de todos os atletas (situação que gera questionamentos acerca dos motivos pelos quais um órgão tão relevante não mantém tais registros), existe a necessidade de recorrer às fontes secundárias não oficiais de pesquisa.

Nesse sentido, no intuito de alcançar os objetivos propostos neste estudo, foi realizado, primeiramente, um levantamento baseado nos dados do site oficial do COI (https://www.olympic.org) e no site oficial dos Jogos Olímpicos Rio-2016 (https://www. rio2016.com.br) de todas as medalhas distribuídas na edição brasileira dos Jogos. Por meio de planilha eletrônica, as medalhas distribuídas em todos os esportes foram catalogadas, verificando o nome completo do atleta, o país pelo qual competiu, o esporte, a modalidade, a categoria, o tipo de competição (individual ou coletiva), o sexo e o tipo de medalha conquistada (ouro, prata ou bronze). No caso dos esportes coletivos foram catalogadas as medalhas de todos os atletas contemplados nas respectivas equipes medalhistas.

1 Os termos importadores e exportadores de medalhas serão utilizados de forma semelhante ao proposto por Oett| e Agrawal (2008), Horowitz e McDaniel (2015) e Jansen e Engbersen (2017). 
Uma vez finalizada a fase de catalogação das medalhas dos Jogos Rio-2016, realizou-se um levantamento do local de nascimento de cada atleta. Essa etapa foi concretizada por meio do cruzamento dos dados dos sites oficiais do $\mathrm{COI}$, do comitê organizador dos Jogos Rio-2016, dos comitês olímpicos de cada país, das federações internacionais de cada esporte, de bases de dados independentes, além das páginas oficiais dos atletas e de notícias relacionadas ao tema em diferentes veículos da mídia esportiva.

Considerando que para a Carta Olímpica do COI os atletas devem representar os países pelos quais são nacionais (independentemente da conexão existente) e que a naturalização pode ser adquirida de inúmeras formas (JANSEN; OONK; ENGBERSEN, 2018), este estudo utilizou os países de nascimento e os países pelos quais os atletas competiram como parâmetros para analisar a migração esportiva no âmbito dos Jogos Olímpicos, haja vista que representam ao menos uma avaliação física quanto ao local de origem e de representação por parte dos atletas (HOROWITZ; MCDANIEL, 2015; JANSEN; ENGBERSEN, 2017; JANSEN; OONK; ENGBERSEN, 2018).

Desse modo, com fito em estruturar o conjunto de dados a ser analisado, as medalhas conquistadas por atletas nascidos nos mesmos países que estavam representando foram classificadas como "medalhas nativas", enquanto as medalhas conquistadas por atletas nascidos em países diferentes daqueles pelos quais competiram foram classificadas como "medalhas naturalizadas".

Quanto ao fluxo migratório relacionado ao desempenho econômico, foi adotado como parâmetro o Produto Interno Bruto (PIB) per capita de cada país medalhista, de acordo com os dados do Banco Mundial (https://data.worldbank.org). Já no que diz respeito ao desempenho olímpico, adotou-se enquanto critério a classificação, de acordo com o COI, de cada país nos Jogos Olímpicos Rio-2016.

\section{APRESENTAÇÃO E DISCUSSÃO DOS DADOS}

Foram catalogadas 2.025 medalhas distribuídas nos Jogos Olímpicos Rio-2016. Do total de medalhas, 135 , ou $6,7 \%$, foram entregues para atletas que competiram por um país diferente do de origem. Das 135 medalhas naturalizadas, 39 foram de ouro, 43 de prata e 53 de bronze.

Nos Jogos Olímpicos Rio-2016, 1.857 atletas foram premiados com medalhas. Deste total, 128 atletas, ou seja, aproximadamente 6,9\%, competiram por um país diferente do de sua origem. Esse resultado corresponde ao maior valor absoluto e ao maior percentual de atletas medalhistas naturalizados se considerarmos as demais edições dos Jogos Olímpicos de Verão do século XXI, conforme é possível observar na Tabela 1. 
Tabela 1 - Atletas medalhistas naturalizados entre as edições 2004 e 2016

\begin{tabular}{cccc}
\hline Ano & Total de atletas medalhistas & Total de atletas naturalizados medalhistas & Percentual \\
\hline 2004 & 1840 & 116 & $6,3 \%$ \\
2008 & 1874 & 92 & $4,9 \%$ \\
2012 & 1770 & 120 & $6,8 \%$ \\
2016 & 1857 & 128 & $6,9 \%$ \\
\hline
\end{tabular}

Fonte: Adaptado de Horowitz e McDaniel (2015).

É mister salientar que cada país conta com um padrão de migração diferente e que deriva de uma grande diversidade de características. Todavia, conforme reflexão de Jansen e Engbersen (2017), a maior frequência de migração da força de trabalho de atletas altamente qualificados (medalhistas olímpicos) parece estar de acordo com o que seria esperado das políticas de imigração e programas de vistos em muitos países que favorecem a migração de mão de obra qualificada.

No que diz respeito ao sexo dos atletas, verificou-se que das 135 medalhas naturalizadas, 83 foram entregues para atletas do sexo masculino $(61,4 \%)$ e 52 para atletas do sexo feminino (38,6\%). Considerando que a distribuição de atletas participantes nos Jogos foi de $54 \%$ para o sexo masculino e $46 \%$ para o sexo feminino, verifica-se que, em consonância com os apontamentos de Maguire (1996) e Pisani (2014), os resultados dos Jogos Olímpicos do Rio de Janeiro indicam que o fluxo migratório no esporte de alto rendimento ainda é predominantemente masculino.

Cabe salientar que esse panorama não segue a tendência encontrada nos fluxos migratórios internacionais. Apesar de o deslocamento feminino ainda ser invisibilizado, em comparação ao dos homens, atualmente a migração internacional é majoritariamente feminina, possível consequência da feminização da pobreza e das grandes desigualdades econômicas ao redor do mundo (BERTOLDO, 2018). Desse modo, é necessário que mais estudos aprofundem essa contradição, apresentando as possíveis causas que levam o fluxo migratório no esporte a ainda ser predominantemente masculino.

Uma das possíveis causas pode estar relacionada ao fato de muitas mulheres repensarem suas carreiras esportivas quando da intenção de se tornarem mães, haja vista que a dificuldade de conciliar uma rotina intensa de treinamento com as obrigações parentais, bem como a incerteza de apoio institucional, faz com que haja a priorização de um espaço em detrimento de outro.

Ao adentrar na distribuição de medalhas naturalizadas entre os países, verifica-se que os países que mais "exportaram" medalhas foram Rússia, Ucrânia e Cuba, seguidos por Armênia, Estados Unidos, Reino Unido, Bósnia, Montenegro e Quênia, conforme é possível observar na Tabela 2. 
Tabela 2 - Países que mais exportaram medalhas naturalizadas na edição Rio-2016

\begin{tabular}{cc}
\hline País & Número de "medalhas naturalizadas" exportadas \\
\hline Rússia & 12 \\
Ucrânia & 9 \\
Cuba & 7 \\
Armênia & 6 \\
Estados Unidos & 6 \\
Grã-Bretanha & 6 \\
Alemanha & 4 \\
Bósnia & 4 \\
Montenegro & 4 \\
Quênia & 4 \\
África do Sul & 3 \\
Austrália & 3 \\
Cazaquistão & 3 \\
Croácia & 3 \\
França & 3 \\
Maláui & 3 \\
Quirguistão & 3 \\
\hline
\end{tabular}

Fonte: Os Autores (2020)

Em relação à distribuição entre os países, verificou-se uma grande quantidade de medalhas naturalizadas exportadas por nações com menor expressão no esporte de alto rendimento como, por exemplo, Ucrânia, Armênia, Bósnia, Montenegro e África do Sul. Entretanto, países com grande potencial olímpico, como Alemanha, GrãBretanha, Estados Unidos e Rússia, também figuram entre os maiores exportadores de atletas olímpicos para outras nações.

Ainda em relação às nações, a Tabela 3 apresenta os países que mais "importaram" medalhas. A lista apresenta como principais importadores Rússia, Azerbaijão, Estados Unidos, Sérvia, Austrália, Grã-Bretanha, Alemanha, Espanha, Canadá e Itália. 
Tabela 3 - Países que mais importaram medalhas naturalizadas na edição Rio-2016

\begin{tabular}{cc}
\hline País & Número de medalhas importadas \\
\hline Rússia & 17 \\
Azerbaijão & 13 \\
Estados Unidos & 12 \\
Sérvia & 12 \\
Austrália & 11 \\
Grã-Bretanha & 11 \\
Alemanha & 9 \\
Espanha & 6 \\
Canadá & 5 \\
Itália & 5 \\
Cazaquistão & 4 \\
Nova Zelândia & 4 \\
França & 3 \\
Turquia & 3 \\
Bahrein & 2 \\
Belarus & 2 \\
Suíça & 2 \\
\hline
\end{tabular}

Fonte: Os Autores (2020)

Ao analisar os países que mais importaram medalhas naturalizadas torna-se mais clara a proeminência de países com alto desempenho nos aspectos econômicos e olímpicos. Com exceção do Azerbaijão e da Sérvia, todos os demais países que figuram entre os dez principais importadores de medalhas naturalizadas estão entre as vinte maiores potências econômicas do mundo ${ }^{2}$ ou entre os vinte mais bem classificados nos Jogos Olímpicos Rio-2016.

É importante destacar ainda o fato de que Rússia, Estados Unidos, GrãBretanha e Alemanha estão entre os países que mais importaram e exportaram medalhas. O grande índice de importação pode ser explicado pela atratividade das nações, com altos níveis de desempenho econômico e esportivo. Já no que tange ao nível de exportação, é mister ressaltar que em alguns esportes a disputa por uma vaga nas seleções olímpicas nacionais é muito acirrada (PHELPS; ABRAHAMSON, 2009), o que também pode contribuir para a naturalização de atletas que não teriam mais espaço nas seleções dos seus países de origem, mas com grande possibilidade de atuar em países de menor tradição em suas modalidades específicas. Acerca disso, Reiche e Tinaz (2019) salientam que é mais fácil para um atleta de alto nível se qualificar para competições internacionais quando representa nações esportivas mais fracas.

Ainda no que concerne aos países, outro fator analisado foi o percentual de medalhas importadas em relação ao total de medalhas conquistadas por cada nação. A Tabela 4 apresenta a lista dos países que conquistaram ao menos $10 \%$ de suas medalhas com atletas naturalizados.

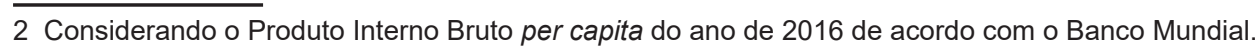


Tabela 4 - Países com o maior percentual de medalhas naturalizadas na edição Rio-2016

\begin{tabular}{ccc}
\hline País & $\begin{array}{c}\text { Percentual de medalhas } \\
\text { conquistadas por atletas de } \\
\text { origem do próprio país }\end{array}$ & Percentual de medalhas importadas \\
\hline Bahrein & $0,0 \%$ & $100,0 \%$ \\
Emirados Árabes Unidos & $0,0 \%$ & $100,0 \%$ \\
Moldávia & $0,0 \%$ & $100,0 \%$ \\
Azerbaijão & $33,3 \%$ & $66,7 \%$ \\
Turquia & $62,5 \%$ & $37,5 \%$ \\
Cazaquistão & $76,5 \%$ & $23,5 \%$ \\
Sérvia & $77,8 \%$ & $22,2 \%$ \\
Suíça & $81,8 \%$ & $18,2 \%$ \\
Belarus & $83,3 \%$ & $16,7 \%$ \\
Rússia & $85,2 \%$ & $14,8 \%$ \\
Grécia & $85,7 \%$ & $14,3 \%$ \\
Austrália & $86,6 \%$ & $13,4 \%$ \\
Espanha & $86,7 \%$ & $13,3 \%$ \\
Nova Zelândia & $88,9 \%$ & $11,1 \%$ \\
\hline
\end{tabular}

Fonte: Os Autores (2020)

A partir da análise dos dados, merecem destaque os casos de Bahrein, Emirados Árabes Unidos e Moldávia, que conquistaram medalhas apenas com atletas que nasceram em outras nações. Dessa forma, não há como afirmar que o fluxo migratório beneficia apenas países de grande potencial esportivo, uma vez que, sem a inclusão dos atletas naturalizados, os países supracitados não figurariam no quadro de classificação dos Jogos Olímpicos do Rio de Janeiro.

Em se tratando especificamente do Bahrein, cabe salientar que, diferentemente de Emirados Árabes Unidos e Moldávia ${ }^{3}$, o país não teve nenhum atleta de sua origem medalhista na Rio-2016. Além disso, destaca-se que as duas medalhas conquistadas pelo Bahrein vieram de atletas nascidas no Quênia. Hipoteticamente, caso essas medalhas não fossem conquistadas pelo país asiático e sim pelo país africano, este último subiria duas posições no quadro de classificação geral, deixando a $15^{\circ}$ e passando a ocupar a $13^{a}$ posição, ultrapassando inclusive o Brasil (país-sede do evento).

Simiyu Njororai (2010) contextualizou o fenômeno envolvendo a migração de atletas do Quênia para outros países. Conforme aponta o autor, a natureza desequilibrada da riqueza global e do poder corporativo criou um movimento de talentos esportivos de clubes e nações que pagam menos para clubes e nações que pagam mais. Além disso, aponta que o domínio de atletas quenianos em corridas de média e longa distância, aliado à escassez de talentos, criou um fluxo migratório de mão de obra esportiva da África para os países ricos em petróleo, mas carentes em talento.

O Quênia figurou entre os dez países que mais exportaram medalhas naturalizadas nos Jogos Olímpicos Rio-2016, porém ainda conseguiu uma boa classificação no quadro geral de medalhas ( $15^{\circ}$ lugar). Entretanto, conforme apontado

3 Apesar da exclusividade de medalhas naturalizadas, Emirados Árabes Unidos e Moldávia tiveram atletas de suas respectivas origens vencendo competições por outras nações. 
por Horowitz e McDaniel (2015), existem casos em que a nação não é reconhecida ou contabilizada na classificação de medalhas, mesmo com atletas de sua origem vencendo as competições. Especificamente na Rio-2016, esse foi o caso de Bósnia, Gana, Maláui, Montenegro, Quirguistão, Senegal, Somália, Turquemenistão e Uganda.

Quanto à análise do fluxo migratório das "medalhas naturalizadas" sob viés econômico, constatou-se que a maior parte dos atletas (72,59\%) e, por conseguinte, das medalhas, migrou de um país de menor desempenho econômico para um de maior desempenho, conforme demonstra a Tabela 5.

Tabela 5 - Fluxo migratório das medalhas naturalizadas na Rio-2016 - desempenho econômico

\begin{tabular}{lcc}
\hline & $\begin{array}{c}\text { Menor desempenho econômico para } \\
\text { maior desempenho econômico }\end{array}$ & $\begin{array}{c}\text { Maior desempenho econômico para } \\
\text { menor desempenho econômico }\end{array}$ \\
\hline Quantidade & 98 & 37 \\
Percentual & $72,6 \%$ & $27,4 \%$ \\
\hline
\end{tabular}

Fonte: Os Autores (2020)

Desse modo, em consonância com Horowitz e McDaniel (2015), os resultados do presente estudo apontam que nações de alta renda e com maiores níveis de PIB apresentam maior possibilidade de atrair talentos estrangeiros nos esportes. Assim como acontece em outros mercados, os países mais ricos são considerados mais atraentes para a mão de obra altamente qualificada.

Tertuliano et al. (2018) analisaram os motivos e intenções de expatriação por voleibolistas e demonstraram que o fator que mais motivou o processo de migração dos atletas foi a busca pelo aumento salarial. Para os participantes do estudo, o salário foi determinante para aceitar o processo de expatriação. Resultados semelhantes também foram observados em estudos com outros esportes olímpicos (PISANI, 2014; SIMIYU NJORORAI, 2010; TIESLER, 2016) e esportes não olímpicos (DIMEO; RIBEIRO, 2009).

Para Spiro (2012), é importante salientar que a crescente prática de naturalizações (sobretudo as instrumentais) propicia um contexto de "fuga de músculos" dos países pobres para os países ricos, além de contribuir para a consolidação de regimes de nacionalização mais flexíveis e que são muito vantajosos aos países mais ricos.

Já no que diz respeito ao fluxo migratório de medalhas considerando o aspecto esportivo, os dados demonstram que maioria dos atletas $(62,2 \%)$ migrou de um país de menor desempenho olímpico para um país de maior desempenho olímpico, conforme apresenta a Tabela 6. 
Tabela 6 - Fluxo migratório das medalhas naturalizadas na Rio-2016 - desempenho olímpico

\begin{tabular}{lcc}
\hline & $\begin{array}{c}\text { Menor desempenho olímpico para } \\
\text { maior desempenho econômico }\end{array}$ & $\begin{array}{c}\text { Maior desempenho olímpico para } \\
\text { menor desempenho olímpico }\end{array}$ \\
\hline Quantidade & 84 & 51 \\
Percentual & $62,2 \%$ & $37,8 \%$ \\
\hline
\end{tabular}

Fonte: Os Autores (2020)

Desse modo, observou-se que os dados dos Jogos Olímpicos Rio-2016 corroboram os estudos que apontam para a procura de oportunidades em nações que permitam o pleno desenvolvimento dos atletas, contribuindo para uma melhora no desempenho e, por conseguinte, nos resultados alcançados nos Jogos Olímpicos (HOROWITZ; MCDANIEL, 2015; MAGUIRE; PEARTON, 2000; MELO; ROCHA JUNIOR, 2012; RIBEIRO et al., 2013; SOCA, 2012; SPIRO, 2012). Desse modo, a naturalização pode ser explicada pela baixa taxa de desenvolvimento no esporte pelo país exportador e alto desejo de prestígio internacional pelo atleta e país importador.

Entretanto, o fluxo migratório das medalhas de países de maior desempenho olímpico para países de menor desempenho olímpico não pode ser desprezado. Conforme demonstrado por Spiro (2012), esse processo pode ocorrer como uma das principais alternativas aos países com pouca tradição no esporte em figurar no cenário olímpico.

Acerca disso, cabe destacar a situação do Azerbaijão. Apesar de não ser uma potência econômica e olímpica, o país foi o segundo que mais importou medalhas na Rio-2016, tendo $66,7 \%$ de suas conquistas vencidas por atletas de outras origens. $\mathrm{E}$ esse contexto não se limita apenas aos esportes olímpicos, haja vista que na Copa do Mundo de futsal realizada entre setembro e outubro de 2016, por exemplo, a equipe azeri chegou até as quartas de final (resultado de destaque para o país) contando em seu elenco com seis atletas de origem brasileira ${ }^{4}$.

Por fim, cabe ponderar que, a despeito de ter se tornado mais fácil, o processo de naturalização não eliminou as dificuldades enfrentadas pelos atletas. Mesmo no caso de expatriação, quando o atleta mantém a sua nacionalidade, o processo migratório pode causar desconforto e insegurança (TERTULIANO et al., 2018). Conforme aponta Rubio (2016), o deslocamento provocado pela necessidade de condições para o desenvolvimento da carreira esportiva culmina em um processo de adaptação, socialização e aculturação muitas vezes de difícil assimilação. Para o atleta que se desloca entre países, principalmente aquele que se naturaliza, o processo pode ser potencializado, envolvendo agravantes como o preconceito e a discriminação.

\section{CONSIDERAÇÕES FINAIS}

A presente pesquisa teve como objetivo descrever a incidência de medalhistas olímpicos naturalizados nos Jogos Olímpicos do Rio de Janeiro em 2016. Foi realizado um levantamento de todas as medalhas distribuídas na edição carioca dos

4 DILASCIO, Flávio. Futsal globalizado: Mundial terá 25 brasileiros defendendo outros países. GE:Futsal, 7 set. 2016. Disponível em: http://globoesporte.globo.com/eventos/futsal/noticia/2016/09/futsal-globalizado-mundial-tera25-brasileiros-defendendo-outros-paises.html. Acesso em: 1 ago. 2020. 
Jogos e uma análise da naturalização de atletas entre os países participantes e do fluxo migratório em decorrência do desempenho econômico e esportivo das nações.

Desse modo, constatou-se que das 2.025 medalhas distribuídas, 135 foram conquistadas por atletas naturalizados, o que representa $6,7 \%$ do total. Dos 1.875 atletas vencedores de medalhas, 128 são imigrantes, representando aproximadamente $6,9 \%$ do total. Constatou-se que o percentual de vencedores de medalhas que são imigrantes é maior do que a porcentagem da população mundial de migrantes.

Rússia, Ucrânia, Cuba, Armênia, Estados Unidos, Reino Unido, Bósnia, Montenegro e Quênia foram os países que mais exportaram medalhas. Por outro lado, Rússia, Azerbaijão, Estados Unidos, Sérvia, Austrália, Grã-Bretanha, Alemanha, Espanha, Canadá e Itália foram os países que mais importaram. Os resultados apontam ainda que o fluxo migratório de atletas naturalizados ocorreu, em sua maioria, de países com pior desempenho econômico e olímpico para países com melhor desempenho econômico e olímpico.

Enquanto limitações do estudo, destaca-se a necessidade de utilização de dados não oficiais, haja vista a inexistência de uma base de dados oficial que contenha as informações sobre os locais de nascimento dos atletas. Conforme apontam Jansen e Engbersen (2017) e Jansen, Oonk e Engbersen (2018), seria de extrema importância para as pesquisas científicas que as organizações envolvidas (COI, comitês olímpicos internacionais e federações internacionais) iniciassem um processo retroativo de registro das naturalizações, incluindo informações sobre o tempo e os motivos para as mudanças de nacionalidade, bem como sobre a condição de cidadania de cada atleta.

Não obstante tais limitações, o presente estudo se mostrou válido em seu objetivo descritivo de contextualizar o atual panorama das naturalizações nos Jogos Olímpicos de verão. Por meio dos resultados encontrados é possível concluir que o processo de migração de atletas tende a ser para as grandes potências econômicas e esportivas uma oportunidade de reforçar e ampliar a hegemonia, enquanto para as grandes potências econômicas, mas pouco desenvolvidas no esporte, uma oportunidade de entrar no circuito olímpico. Já para os países economicamente pobres, o fluxo migratório se apresenta como uma grande desvantagem competitiva.

Conforme apontam Horowitz e McDaniel (2015), as nações de maior poderio econômico e esportivo têm se mostrado capazes de tirar proveito das várias motivações de migração para atrair atletas de grande potencial olímpico. Se o país de destino oferece melhores condições financeiras e de treinamento, mais oportunidades de competir em alto nível, além da própria chance de criar uma vida melhor fora dos esportes, o apelo é tão grande que torna o país de origem muito vulnerável ao êxodo dos seus atletas de alto nível.

Desse modo, torna-se importante suscitar questionamentos em novas oportunidades acerca das políticas públicas para o esporte de alto rendimento. Considerando a facilitação no processo de naturalização de atletas por algumas nações, é possível que o investimento realizado na formação e desenvolvimento de atletas não se materialize em resultados futuros para o país formador. Além 
disso, em pesquisas futuras, recomenda-se o aprofundamento das causas que levam o fluxo migratório no esporte ainda ser predominantemente masculino. Novos estudos poderão ainda ser realizados no intuito de analisar a incidência de medalhas naturalizadas e as tendências no fluxo migratório de atletas nas diferentes modalidades olímpicas.

\section{REFERÊNCIAS}

AGERGAARD, Sine. Learning in landscapes of professional sports: transnational perspectives on talent development and migration into Danish women's handball around the time of the financial crisis, 2004-2012. Sport in Society, v. 20, n. 10, p. 1457-1469, 2017.

ALMEIDA, William Douglas de; RUBIO, Kátia. Novos brasileiros nos jogos olímpicos: a presença de migrantes internacionais na delegação do país na Rio-2016. Revista Brasileira de Ciência e Movimento, v. 26, n. 1, p.131-142, 2018.

ANDREFF, Wladimir. Why tax international athlete migration? The 'Coubertobin' tax in a context of financial crisis. In: MAGUIRE, Joseph; FALCOUS, Mark. (ed.). Handbook on sport and migration: borders, boundaries and crossings. Oxon: Routledge, 2010. p. 31-45.

ASIS, Maruja; PIPER, Nicola. Researching international labour migration in Asia. The sociological quarterly, v. 49, n. 3, p. $423-444,2008$.

BERTOLDO, Jaqueline. Migração com rosto feminino: múltiplas vulnerabilidades, trabalho doméstico e desafios de políticas e direitos. Revista Katálysis, v. 21, n. 2, p. 313-323, 2018.

BESNIER, Niko. Sports mobilities across borders: postcolonial perspectives. The International Journal of the History of Sport, v. 32, n. 7, p. 849-861, 2015.

BETTINE, Marco; GUTIERREZ, Diego; GRAEFF, Billy. As reportagens das mídias estrangeiras sobre o Brasil dos megaeventos esportivos: soft power, periferia e dependência. Movimento (Porto Alegre), v. 24, n. 4, p. 1353-1368, jan. 2018. DOI: https://doi.org/10.22456/1982-8918.82438

CHEQUER, Najla Emiline; MARTINS, Mariana Zuaneti; SILVA, Otávio Guimarães Tavares da. Os brasileiros e a Copa no Brasil: o antes, durante e depois da competição sob as lentes de O Globo. Movimento (Porto Alegre), v. 24, n. 4, p. 1125-1138, jan. 2019. DOI: https:// doi.org/10.22456/1982-8918.76728

CHIBA, Naoki; EBIHARA, Osamu; MORINO, Shinji. Globalization, naturalization and identity: The case of borderless Elite Athletes in Japan. International Review for the Sociology of Sports, v. 36, p. 203-221, 2001.

DILASCIO, Flávio. Futsal globalizado: Mundial terá 25 brasileiros defendendo outros países. GE:Futsal, 7 set. 2016. Disponível em: http://globoesporte.globo.com/eventos/futsal/ noticia/2016/09/futsal-globalizado-mundial-tera-25-brasileiros-defendendo-outros-paises. html. Acesso em: 1 ago. 2020.

DIMEO, Paul; RIBEIRO, Carlos Henrique. 'I am not a foreigner anymore': a microsociological study of the experiences of Brazilian futsal players in European leagues. Movimento (Porto Alegre), v. 15, n. 2, p. 33-44, fev. 2009. DOI: https://doi. org/10.22456/1982-8918.3082 
FAGGIANI, Fernanda et al. O fenômeno do expatriado no contexto esportivo. Psicologia: ciência e profissão, v. 36, n. 3, p. 738-747, 2016.

HOROWITZ, Jonathan; MCDANIEL, Stephen. Investigating the global productivity effects of highly skilled labour migration: How immigrant athletes impact Olympic medal counts. International Journal of Sport Policy and Politics, v.7, n.1, p. 19-42, 2015.

JANSEN, Joost; ENGBERSEN, Godfried. Have the Olympic games become more migratory? a comparative historical perspective. Comparative Migration Studies, v. 5, n. 11, 2017. DOI: 10.1186/s40878-017-0054-2

JANSEN, Joost; OONK, Gijsbert; ENGBERSEN, Godfried. Nationality swapping in the Olympic field: towards the marketization of citizenship? Citizenship Studies, v. 22, n. 5, p. 523-539, 2018.

INTERNATIONAL OLYMPIC COMMITTEE (IOC). Olympic Charter. Lausanne: Maison Olympique, oct. 2020. Disponível em: https://olympics.com/ioc/olympic-charter Accessed on: Aug. $1^{\text {st }}, 2020$.

MAGUIRE, Joseph. Blade Runners: Canadian migrants, ice hockey and the global sports process. Journal of Sport and Social Issues, v. 20, n 3, p. 335-360, 1996.

MAGUIRE, Joseph. 'Política’ o ‘Ética': deporte, globalización, migración y políticas nacionales. EFDeportes.com: Revista Digital - Buenos Aires, v. 12, n.111, 2007. Disponível em: https://www.efdeportes.com/efd111/deporte-globalizacion-migracion-y-politicasnacionales.htm Acesso em: 1 ago. 2020.

MAGUIRE, Joseph; PEARTON, Robert. The impact of elite labour migration on the identification, selection and development of European soccer players. Journal of Sports Sciences, v. 18, n. 9, p. 759-769, 2000.

MELO, Victor Andrade de; ROCHA JUNIOR, Coriolano Pereira da. Esporte, póscolonialismo, neocolonialismo: um debate a partir de fintar o destino (1998). Revista Brasileira de Ciências do Esporte, v. 34, n. 1, p. 235-251, 2012.

NASCIMENTO, Diego Ramos do et al. Migração no esporte: uma revisão sistemática. Motrivivência, v. 32, n. 62, p. 1-19, 2020.

OETTL, Alexander; AGRAWAL, Ajay. International labour mobility and knowledge flow externalities. Journal of international business studies, v. 39, n. 8, p. 1242-1260, 2008.

PAES, Viviane Ribeiro; AMARAL, Silvia Cristina Franco. Políticas públicas de esporte educacional em São Paulo: impactos dos Jogos Olímpicos de 2016. Movimento (Porto Alegre), v. 23, n. 2, p. 715-728, 2017. DOI: https://doi.org/10.22456/1982-8918.71006

PHELPS, Michael; ABRAHAMSON, Alan. No limits: The will to succeed. New York: Free Press, 2009.

PISANI, Mariane da Silva. Migrações e deslocamentos de jogadoras de futebol: mercadoria que ninguém compra? Esporte e Sociedade, v. 9, n. 23, 2014. Disponível em: https:// periodicos.uff.br/esportesociedade/article/view/49207. Acesso em: 20 out. 2020.

PONTES, Vanessa Silva et al. Migração no voleibol brasileiro: a perspectiva de atletas e treinadores de alto rendimento. Movimento (Porto Alegre), v. 24, n. 1, p. 187-198, 2018. DOI: https://doi.org/10.22456/1982-8918.66495 
REICHE, Danyel; TINAZ, Cem. Policies for naturalisation of foreign-born athletes: Qatar and Turkey in comparison. International Journal of Sport Policy and Politics, v.11, n.1, p. 153171, 2019.

RIBEIRO, Carlos Henrique Vasconcellos; LOVISOLO, Hugo; GOMES, Alberto; SANT'ANNA, Andrezza. Tem um queniano correndo entre nós: atletismo e migração no Brasil. Revista Brasileira de Educação Física e Esporte, v. 27, n. 3, p. 401-410, 2013.

RICHARDSON, David; LITTLEWOOD, Martin; NESTI, Mark; BENSTEAD, Luke.

An examination of the migratory transition of elite young European soccer players to the English premier league. Journal of Sport Sciences, v. 30, n. 15, p. 1605-1618, 2012.

RICHARDSON, Roberto Jarry. Pesquisa social: métodos e técnicas. 3. ed. 14. reimpressão. São Paulo: Atlas, 2012.

RUBIO, Kátia. Mover, mudar, migrar - por que atletas se deslocam pelo mundo afora? Jornal da USP, 12 de dezembro de 2016. Disponível em: http://jornal.usp.br/artigos/movermudar-migrar-por-que-atletas-se-deslocam-pelo-mundo-a-foral. Acesso em: 5 ago. 2020.

RUBIO, Kátia. Processos migratórios e deslocamentos: Caminhos que levaram atletas de modalidades coletivas aos Jogos Olímpicos de Barcelona em 1992. Olimpianos - Journal of Olympic Studies, v. 1, n.1, p. 53-67, 2017.

SAMPIERI, Roberto Hernández; COLLADO, Carlos Fernández; LUCIO, María del Pilar Baptista. Metodologia de pesquisa. 5. ed. Porto Alegre: Penso, 2013.

SANTOS, Doiara Silva dos. Os Jogos Pan-americanos e o enraizamento do movimento olímpico na América Latina. Movimento (Porto Alegre), v. 23, n. 3, p. 989-1000, set. 2017. DOI: https://doi.org/10.22456/1982-8918.72860

SHOR, Eran; YONAY, Yuval. Sport, national identity, and media discourse over foreign athletes in Israel. Nationalism and Ethnic Politics, v. 16, n. 3-4, p. 483-503, 2010.

SILVA, Emília Amélia Pinto Costa da et al. O jogo das cidades em tempos de megaeventos esportivos: algumas reflexões. Movimento (Porto Alegre), v. 21, n. 1, p. 249-260, 2015. DOI: https://doi.org/10.22456/1982-8918.42893

SIMIYU NJORORAI, Wycliffe W. Global inequality and athlete labour migration from Kenya. Leisure/Loisir, v. 34, n. 4, p. 443-461, 2010.

SOCA, Dante, Steffano. Deporte y migración: aportes para sucomprensión desde el caso uruguayo. Revista da ALESDE, v. 2, n. 2, p. 33-43, 2012.

SPIRO, Peter John. The end of Olympic nationality. In: JENKINS, Fiona; NOLAN, Mark; RUBENSTEIN, Kim. Allegiance and identity in a globalised world. Cambridge: Cambridge University, 2012. p. 478-496.

TERTULIANO, Ivan Wallan et al. Motivos e intenções para expatriação de voleibolistas. Revista de Administração Contemporânea, v. 22, n.4, p. 531-551, 2018.

TIESLER, Nina Clara. Three types of transnational players: differing women's football mobility projects in core and developing countries. Revista Brasileira de Ciências do Esporte, v. 38, n. 2, p. 201-210, 2016. 
Abstract: This research describes the occurrence of naturalized Olympic medalists at the 2016 Rio de Janeiro Olympics. It is a quantitative, descriptive study. The results show that $6.6 \%$ of the medals were given to naturalized athletes, which account for $6.9 \%$ of all medal-winning athletes. The results also point out that most of the migratory flow of medalists came from countries with lower economic and Olympic performance. The findings indicate that the current context of athletes' naturalization tends to be more beneficial to countries with high economic and Olympic performance as well as those with high economic performance but low tradition in sports, therefore being disadvantageous to countries with low economic performance.

Keywords: Sports. Human migration. Athletes. Medals.

Resumen: El objetivo de este estudio fue describir la incidencia de medallistas olímpicos naturalizados en los Juegos Olímpicos de Rio de Janeiro en 2016. Es una investigación cuantitativa con carácter descriptivo. Los resultados muestran que el $6,7 \%$ de las medallas se distribuyeron entre deportistas naturalizados, lo que corresponde a un 6,9\% del total de deportistas medallistas. Los resultados también muestran que la mayor parte del flujo migratorio de atletas medallistas se dio desde países con menor desempeño económico hacia los de mayor desempeño económico y desde países con menor desempeño olímpico hacia países con mayor desempeño olímpico. Las conclusiones indican que el actual contexto de naturalización de deportistas tiende a ser más beneficioso para los países con alto rendimiento económico y olímpico, así como para países con alto rendimiento económico, pero sin tradición en el deporte, al tiempo que implica desventaja para países con bajo rendimiento económico.

Palabras clave: Deportes. Migración humana. Atletas. Medallas. 


\section{LICENÇA DE USO}

Este é um artigo publicado em acesso aberto (Open Access) sob a licença Creative Commons Atribuição 4.0 Internacional (CC BY 4.0), que permite uso, distribuição e reprodução em qualquer meio, desde que o trabalho original seja corretamente citado. Mais informações em: https://creativecommons.org/licenses/by/4.0

\section{CONFLITO DE INTERESSES}

Os autores declararam que não existe nenhum conflito de interesses neste trabalho.

\section{CONTRIBUIÇÕES AUTORAIS}

Diogo Bonin Maoski: Conceituação, Investigação, Escrita.

Ana Paula Cabral Bonin Maoski: Conceituação, Investigação, Escrita.

Thiago de Oliveira Santos: Conceituação, Revisão.

Fernando Marinho Mezzadri: Revisão.

Thiago Cavalcante Nascimento: Revisão, Supervisão.

\section{FINANCIAMENTO}

O presente trabalho foi realizado sem o apoio de fontes financiadoras.

\section{ÉTICA DE PESQUISA}

O projeto de pesquisa seguiu os protocolos do Guia de Integridade em Pesquisa Científica da Universidade Federal do Rio Grande do Sul.

\section{COMO REFERENCIAR}

MAOSKI, Diogo Bonin; MAOSKI, Ana Paula Cabral Bonin; SANTOS, Thiago de Oliveira; MEZZADRI, Fernando Marinho; NASCIMENTO, Thiago Cavalcante. Sotaque Premiado: A Incidência De Medalhas Naturalizadas Nos Jogos Olímpicos Rio 2016. Movimento (Porto Alegre), v.27, p.e27066, jan./dez. 2021. Disponível em: https://seer.ufrgs.br/Movimento/article/view/109549. Acesso em: [dia] [mês abreviado]. [ano]. DOI: https://doi.org/10.22456/1982-8918.109549

\section{RESPONSABILIDADE EDITORIAL}

Alex Branco Fraga*, Elisandro Schultz Wittizorecki*, Ivone Job*, Mauro Myskiw*, Raquel da Silveira*

*Universidade Federal do Rio Grande do Sul, Escola de Educação Física, Fisioterapia e Dança, Porto Alegre, RS, Brasil. 